\title{
APLICAÇĀO DA GENÉTICA HUMANA À HIGIENE MENTAL. REVISÃO DE 300 MATRIClLAS DO CENTRO DE SAÚDE DE SANTANA
}

\author{
Aníbal Silveira *
}

A partir do início do século, quando se reeditaram as leis de Mendel, a genética humana começoı a predominar gradativamente no pensamento médico. É digno de menção o fato de haverem elas sido apresentadas então, quase simultâneamente (em 1900), por botanistas de três paises e que trabalharam independentemente. Nesse empreendimento, que teve o mérito de despertar prontamente o interêsse do mundo científico, a prioridade coube, sŁgundo se depreende da revisão histórica de Caullery, a De Vries, o qual, logo depois, publicou a obra em dois volumes "Die Mutationstheorie" (1901 a 1903), cujo segundo volume constitui "desenvolvimento das leis de Mendel, reencontradas pelo próprio De Vries" '. Também não foi certamente por mera casualidade que os principios formulados por Mendel tiveram de ser redescobertos para entrar no âmbito clínico. Ao contrário, a explicação do olvido deve procurar-se na falta de amadurecimento do mundo médico na época em que vieram à luz (1865). Aliás, os autores em geral o reconhecem e Caullery ${ }^{1}$ acentua textualmente: "Na realidade, os espíritos não estavam preparados para lhes reconhecer o alcance. A idéia tão fecunda da pureza dos gametos, enunciada igualmente por Naudin, publicada em um dos periódicos mais afamados e em memória que foi consagrada pela mais alta recompensa da Academia de Ciências de Paris, passou também despercebida" (pág. 57). Da mesma forma, não foi o acaso mas a preparação do espírito médico por quase 50 anos, o que permitiu que já desde a primeira década dêste século os estudos sôbre hereditariedade médica se constituissem em disciplina autônoma. E disciplina hoje indispensável para a prática da medicina integral. Por volta de 1920 as pesquisas nesse campo, até então isoladas, passaram a convergir e a se ampliar de maneira sem precedente na história da medicina, até se concentrarem, hoje em dia, em institutos especializados, em tôda a Europa e nos Estados Unidos da América do Norte.

À medida que foi deixando à margem os exageros microbianos e o critério especialístico para compreender as reações humanas como expressões

\footnotetext{
Trabalho do Centro de Saúde de Santana (Diretor: Dr. Philemon P. Ribeiro da Matta), Serviço de Centros de Saúde da Capital, Departamento de Saúde do Estado, São Paulo. Apresentado ao $\mathrm{X}$ Congresso Brasileiro de Higiene, Belo Horizonte (Minas Gerais), em 19 outubro 1952.

* Docente-Livre de Psiquiatria na Fac. Med. da Univ. de São Paulo. Encarregado do Servico de Higiene Mental no Centro de Saúde de Santana.
} 
da personalidade em conjunto, a medicina clínica entrou a delinear cada vez mais claramente os fatôres genéticos da constituição. A respeito desta última, acentua GEDDA ${ }^{3 \mathrm{~b}}$ : "Pois que todos reconhecem a necessidade de que êste assunto passe da fase simpática mas impraticável das histórias clínicas, das intuições e das hipóteses, para uma fase concreta de pesquisa e de aplicação clinica, vale afirmar claramente que as leis sôbre as quais a Medicina pode basear a doutrina da constituição são aquelas focalizadas por uma ciência, a Genética, a qual neste setor particular de aplicação se chama Genética Médica". Por outro lado, como frise Snyder, fôrça é reconhecer que a heredologia tem muito a lucrar com a associação à medicina. São palavras dêsse autor 15a: "A questão do significado exato da imunidade e da suscetibilidade em várias condições mórbidas; os processos embriológicos e evolutivos, pelos quais o fator hereditário produz o caráter final; o acesso a familias em que se encontram os traços clínicos; a compreensão das várias manifestações que determinado traço pode assumir - tôdas essas representam questões em que a genética depende da apreciação médica".

Tal necessidade de orientar o estudo da genética segundo as normas e a finalidade peculiares à medicina não se entende apenas com o aspecto doutrinário; ela prevalece exatamente na aplicação prática da medicina preventiva, quer individual, quer principalmente social. De fato, o campo de ação dêsse conjunto de fenômenos biológicos se estende para muito além do plano individual. Não há exagêro em alegar que mesmo a complexa estrutura das instituições sociais é largamente influenciada pelos componentes heredobiológicos. Ao apreciar a freqüência de doenças ligadas à hereditariedade na Dinamarca, diz Kemp ${ }^{\top}$ :

"Dentre êsses fatôres que determinam a sorte e a sobrevivência de uma raça ou de uma nação, um grupo muito importante se compõe de anomalias, anormalidades, defeitos e doenças, de origem hereditária, que occorem na população.

"Eis porque o estudo das lesões heredológicas é de tão grande alcance para os problemas da população, para a genética humana, a estatística médica, a saúde pública, para os ramos clínico, preventivo e social da medicina, para a sociologia e a política. Manifestam-se nos anos mais recentes, nos países democráticos, uma crescente consciência social, um sentimento cada vez mais intenso de que a sociedade precisa tornar mais tolerável para todos as condições de vida; isto tem exigido o estudo das doenças hereditárias e, não em menor escala, o da freqüência delas na população. $\dot{\mathbf{E}}$ importante, para as fôrças governamentais e para as autoridades públicas, conhecer o número dos que, em razão de lesões hereditárias, são socialmente incapazes e necessitam de assistência social, de tratamento, ou de admissão em hospitais ou em institutos médicos".

Não é, entretanto, apenas êste o escopo das indagações genéticas: outro mais amplo em finalidade, porque preventivo, se desenvolve a partir de tal 
recenseamento médico. Referimo-nos ao prognóstico quanto à higidez de cada linhagem humana em estudo e, portanto, dos individuos que a representam no momento dado. Essa previsão, ainda naturalmente empírica, corresponde à principal missão do eugenista e nela se baseará por certo, dentro em pouco, a prática de tôda a medicina. Assim, a investigação das condições mórbidas genèticamente transmissiveis e das circunstâncias em que a transmissão se dá constitui o fundamento para o conselho eugênico. E através dêstc conselho é que poderá o médico agir preventivamente, $\mathrm{cm}$ âmbito social, para que o cabedal humano se depure dos traços indesejáveis, gregàriamente considerados. Tal escopo só se atingirá mediante a orientação médica, no caso eugênica, quanto aos problemas pré-matrimoniais e à composição numérica das famílias. Assinala-o bem Osborn 12: "Alguns individuos serão portadores de genes defeituosos em número muito superior à média; alguns o serão em grau muito inferior a esta. Se o nascimento entre os piores transmissores puder ser levado ao mínimo haverá simultâneamente redução em larga variedade de genes maléficos. Se o nascimento daqueles que carregam o menor número de genes deficitários puder ser ampliado ao máximo, a proporção do cabedal sadio poderá ser aumentada sem que o índice de natalidade precise cair aquém da proporção necessária para a renovação. Para atingir tais resultados seriam necessárias maiores variações no tamanho da família do que as que hoje existem. E variaçōes subordinadas não às diferenças na educação e no padrão de vida, mas às qualidades genéticas comprovadas" (págs. 26-27).

Esta concepção relativa na apreciação do grau de eugenismo ou de indesejabilidade constitui, a nosso ver, o principal progresso na aplicação social da genética humana. Realmente, o individuo indiscutivelmente eugênico e convergente quanto a todos os traços da personalidade moral e somática não existe senão como abstração. Dai, a necessidade de sopesar, pelo aspecto da transmissão biológica e do resultado final para a espécie humana, os vários traços da personalidade. $\mathrm{E}$ seguramente isto faz com que o campo principal da genética humana seja o mundo subjetivo, estudado na arte médica pela psiquiatria. Müller ${ }^{11}$ o exprime bem: "A maioria dentre nós concorda em que, para o homem, o mundo da vida mental é o que mais tem que ser levado em conta: todos os mais aspectos ficam em plano muito subsidiário. É, portanto, evidente que, se acaso chegarmos a ponderar os valores relativos de diferentes genótipos para reprodução, a mais alta prioridade, no todo, seria concedida a.os genes que entendem com a mentalidade — se de alguma forma os pudéssemos avaliar. Ao ler as novas concepções de Einstcin, que sentimento de insuficiência se desperta, mesmo na maioria dos cientistas desta época assim chamada cientifica! Maior capacidade intelectual, e acompanhada de mais apurados sentimentos, constituem seguramente as maiores necessidades biológicas de todo o gênero humano. E assim, embora devamos assiduamente procurar conhecer os princípios que constituem a base genética da saúde somática e da resistência física, bem como os meios de melhorá-las, precisamos não esquecer que a transmissão de uns tantos ge- 
nes de leves doenças somáticas aqui e acolá será habitualmente compensada de muito se ela der margem a algum melhoramento considerável em relação à base genética das características mentais. Devemos ter em mente também que, em tais casos, graças ao processo de recombinação de genes, os genes maléficos poderão ser eliminados e, assim, logo seremos dispensados de manter o compromisso oportunístico referido, pelo qual elementos preciosos eram preservados pelo preço de alguns defeitos físicos" (págs. 165-166).

Só o prisma da genética médica permite distinguir corretamente os traços gregàriamente indesejáveis, os que poderāo ser tolerados e os que constituem fatôres convergentes. Mesmo para o diagnóstico clínico individual e para a prevenção imediata essa disciplina assume valor especial. "Desvios leves mas significativos para com a normalidade — diz Snyder 1.i — que têm sido desprezados pelo médico e pelo paciente ao mesmo tempo, assumirão novo e importante significado à luz da genética, o que dará margem a novos critérios diagnósticos, à identificação precoce e, por conseguinte, a novas oportunidades para a terapêutica e a prevenção". Da mesma forma, correlações entre funções mentais e particularidades de organização somática surgem mais claras quando apreciadas à luz da genética, quer em estado normal, quer no plano das manifestaçōes mórbidas. Exemplo desta fértil indagação médica encontramos no modelar estudo de Kallmann "̄l) (págs. 18-19) : "Alguns dados clínicos registrados na observação a longo prazo de nossa série de pares gêmeos monozigóticos concordantes parecem confirmar a tão discutida teoria de que a instabilidade afetiva e a disfunção bioquímica produzidas pelo genótipo maníaco-depressivo podem exibir largo âmbito de variabilidade fenotípica e são provàvelmente correlatas aos fatôres genéticos para a gôta e o diabetes, especialmente à tendência para a obesidade". Entretanto, não é só no domínio dos distúrbios de funções vegetativas que a genética humana permite conclusões de importância capital e ao mesmo tempo indicar novos rumos para a pesquisa. Também no setor das reações interhumanas - em que as solicitações do ambiente objetivo e social desempenham o papel aparente principal - tal investigaçāo se revela insubstituível. Ainda aquêle mesmo insigne pesquisador ja afirma, ao resumir detido estudo sôbre problemas de ajustamento no homem: "Em particular, pode mostrar-se fàcilmente que constelações semelhantes de experiências infantis desfavoráveis deixam freqüentemente de produzir desvios semelhantes da personalidade em membros genèticamente dissemelhantes da mesma familia; ao passo que cogêmeos semelhantes freqüentes vêzes exibem o mesmo tipo de desajustamento, ainda quando separados em idade muito precoce". Mesmo que os dados originários quanto ao aspecto psicológico sejam discordantes, a indagação genética contribui para a compreensāo dêles: "Outra explicaçāo para as nossas observações sôbre gêmeos - escrevem Kallmann e Anastasio " é que o suicídio parece resultar de fatôres motivantes tāo complexamente combinados que tornam muito improvável a repetição desta incomum conste- 
iação mesmo em co-gêmeos que apresentam o mesmo tipo de psicose e com privações sociais muito similares".

Mesmo para a compreensão dos fatos psicológicos dentro da faixa normal a heredobiologia oferece normas seguras: o comportamento genético dos traços subjetivos da personalidade é o que aí se pesquisa, conforme precisa Schulz ${ }^{1::}$ : "Oz radicais psicológicos não são sempre, de modo algum, heredológicos. Mas aos heredobiológicos estudamos sempre como heredobiológicos, mesmo em relação àquelas propriedades que ùnicamente pela expressão psíquica fodem ser reconhecidas. Não vai nisto diminuição alguma para a psicologia. Mas, da mesma forma que a física nāo pode distinguir de que modo as diversas ondas de éter são percebidas como côres, .... da mesma forma que não è à biologia porém à psicologia que cumpre decidir sôbre a correlação e a compreensão psicológicas de processos psíquicos, assim sòmente a b:ologia pode decidir quanto às correlaçōes biológicas de processos e particularidades psicológicos e a heredobiologia quanto às de ordem heredobiológica" (pag. 22).

Em realidade, o estudo genético das manifestações psíquicas abrange extensa gama de fenômenos, desde aquêles situados em àmbito normal até os que se mostram claramente patológicos. Éstes últimos não consistem apenas nos quadros psiquiátricos endógenos clássicos, ditos constitucionais: mais importantes para a prática clínica são as psicoses reversíveis descritas e exaustivamente estudadas por Kleist ${ }^{8}$, que as denominou "degenerativas". A identificação de tais quadros marginais isolados pelo cminente mestre de Frankfurt-am-Main constitui, a nosso ver, o progresso mais relevante da psiquiatria contemporânea. Cumpre ainda reconhecer as reações psicopatológicas que podem exprimir o feitio mórbido da personalidade e, enfim, os distúrbios momentâneos que apenas revelam, no indivíduo ademais bem enquadrado na população média, a predominância de certos traços heredológicos.

Orientada por êsses conhecimentos, a prevençāo eugênica pode trazer benefícios não só imediatos, para o consulente, mas futuros, para a linhagem biológica que venha a originar. De qualquer forma, a verdadeira higiene mental, a que pode auxiliar a espécie a suportar com menos sofrimento os tormentosos tempos atuais, não se compreende sem a assistência direta da genética humana. E é por isso que temos orientado sob o ascendente dessa disciplina nossa atuaçāo no Serviço de Higiene Mental do Centro de Saúde de Santana.

\section{MATERIAL, METODO E RESULTADOS}

Antes de comeniarmos os dados que julgamos de interêsse convém apresentar algumas rápidas indicacōes sôbre as condicões em que colhemos a material clinico respectivo. Nosso Serviço funciona em correspondência com os demais, que existem em todos os Centros de Saúde da Capital: por um lado, os Serviços de Higiene Prénatal, de Higiene Infantil, de Higiene Pré-escolar e Escolar e o de Exames Médicos 
Periódicos; e por outro lado o Serviço Social, a cargo das visitadoras domiciliares. Nos Serviços internos os médicos têm como auxiliares educadoras sanitárias, cujo conjunto recebe a cooperação da educadora centralizadora e a supervisão da educadora-chefe. Assim, embora cada Serviço opere isoladamente, em geral, o intercámbio de consulentes e de opiniôes médicas se torna fácil mediante o recurso à atuação das educadoras, as quais se incumbem também de orientar os clientes quanto às prescrições médicas. Uma das educadoras - a que atualmente efetua a centralização - se encarrega ainda de agrupar consulentes para discutir problemas que lhes são comuns, ensejo excelente para a psicoterapja coletiva.

Quanto ao nosso trabalho nesse Serviço, devenos assinalar que não dispomos de auxiliares outros, além de uma educadora sanitária em caráter permanente e da educadora centralizadora quando haja necessidade. Assim, o registro metódico dos consulentes e do mterial clínico respectivo representa a única tarefa adicional à sessão clínica, inicial ou de revisão. Ainda não dispomos de auxiliar incumbido de trabalhar estatisticamente, quanto ao aspecto heredobiológico, os dados coligidos. A carência dêste elemento científico faz com que os dados que hoje apresentamos em resumo devam ser interpretados com reserva em referência ao significado heredobiológico, principalmente naquilo que entendem como a incidência percentual dos vários quadros clínicos de ordem hereditária. Todavia, para a diagnose clínica e para a apreciação dos sintomas psicopatológicos não nos valemos do critério fenomenológico, mas sim, como temos mencionado em publicações várias, da interpretação genético-dinâmica em sentido mais rigoroso. Os informes clínicos, diretos e anamnésticos, são colhidos pessoalmente por nós e muita vez exigem, para a devida avaliação, que, além do consulente, entrevistemos outros membros da família melhor informados. Por outro lado, a sessão clinica è naturalmente demorada devido à natureza dos dados subjetivos correspondentes e, além disso, nāo pode encerrar-se, via de regra, na primeira entrevista. Isto explica que não possamos habitualmente atender a mais que 8 consulentes, entre matricula e revisão, em cada expediente.

Entre o periodo de fevereiro de 1952, data em que iniciamos o Servico, e 15 de julho, atendemos a 317 matriculados. Consideramos aqui os dados de interêsse geral relativos às primeiras 300 matriculas consecutivas dêsse cabedal clínico. Assinalamos que tais consulentes não nos foram encaminhados segundo qualquer critério prefixado: êles representam assim, sob êsse aspecto particular -- pelo menos até certo ponto - uma amostra não selecionada da clientela que acorre ao Centro de Saúde de Santana. O encaminhamento, quer por parte dos colegas de trabalho, quer por parte das educadoras ou das visitadoras, era motivado pela existência de dificuldades de natureza psicológica, ora evidentes no comportamento explícito do consulente, ora reveladas ao exame médico. Logo a partir do $2 \circ$ mês do Serviço, é verdade, começaram a procurá-lo espontâneamente clientes do Centro que tomaram conhecimento da possibilidade de assistēncia psicológica direta. Mas a própria ocorrência desta necessidade de assistencia psicológica representa um indice significativo na composição clinica da população ali assistida; indice real, embora antes estivesse mascarado - como talvez suceda em outras unidades de saúde pública - pela não existencia de Serviço explicitamente destinado a esta classe de problemas da personalidade. Mesmo a predominância de manifestaçôes clínicas filiáveis a determinada linhagem heredológica não nos parece resultar ai de artifício na seleção do material clínico - como diremos oportunamente - mas antes corresponder à expressão intrinseca da população média.

Cumpre ainda fazer a ressalva de que apenas em algumas instâncias pudemos examinar diretamente membros da familia imediata do probando, os quais nesse caso, como regra geral, ficaram registrados em fichas "entrosadas" com a do cliente respectivo. Vale dizer que apenas nessa eventualidade dispomos de elementos diretos para avaliar a frequeencia de manifestações clínicas em pessoas da familia do examinando. Na quase totalidade das vêzes a ocorrência de tais traços - mencionada na ficha do examinando - se deduziu apenas do informe anamnéstico das pessoas consideradas aqui na coluna 1 da tabela 1 : 


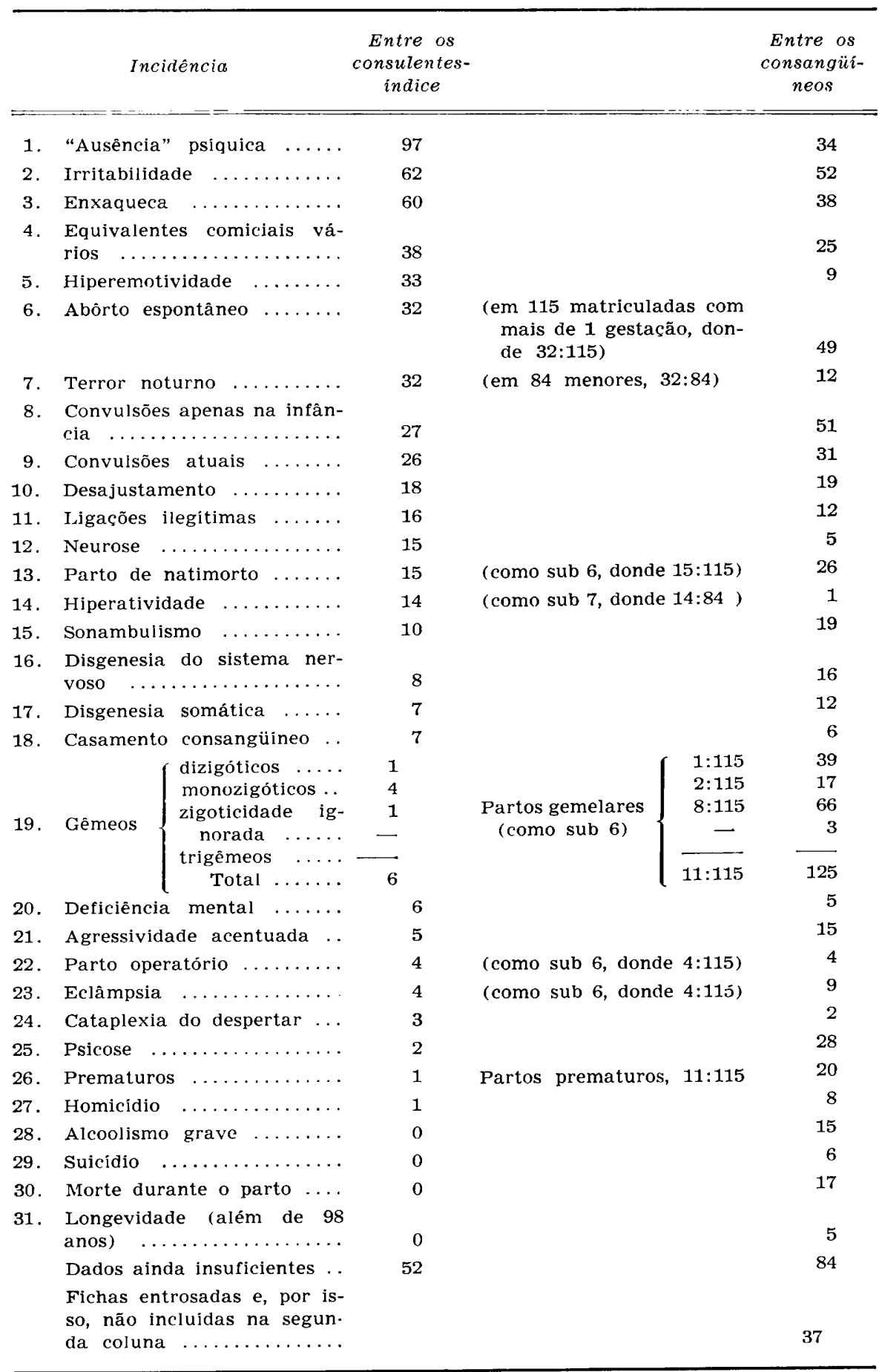

Tabela 1 - Condições clínicas verificadas em 300 matrículas consecutivas. 
Como decorre dessa tabela, anotamos, entre os 300 consulentes-índice, considerados em conjunto, uma série de manifestações clínicas, dentre as quais figuram com maior freqüência as que são reconhecidamente filiáveis ao ciclo heredológico da epilepsia: assim, por ordem decrescente, encontramos aí "ausência" psiquica em $32 \%$, irritabilidade em $20,6 \%$, enxaqueca em $20 \%$, equivalentes vários, de modalidade atípica e de significado claramente epileptóide, em 12,6\%, além de convulsões francas em $8,6 \%$ e convulsões apenas na infância em $9 \%$. Ao lado dessas expressōes clinicas já estabelecidas quanto à diagnose heredológica, outras ocorrências assumem freqüência tal que merecem focalizadas mais detidamente; a elas nos reportaremos dentro em pouco. A indagação da anamnese heredológica nesse grupo total de 300 consulentes revelou a incidência em proporção digna de nota daqueles mesmos traços, embora em ordem diversa. Alinhamos tais freqüências. em números absolutos, na coluna 2 da mesma tabela. Vemos aí que, entre os 300 , se arrolam irritabilidade mórbida na família de $52(17,3 \%)$, convulsões durante a infância na de 51 ( $17 \%$ ), abôrto espontâneo na de $16,3 \%$ dos consulentes, enxaqueca entre os consangüíneos de $12,6 \%$, "ausência" psiquica em relação a 11,3\%, convulsōes com referência a 10,3\%. Segundo assinalamos há pouco, esta revisāo de dados clinicos baseada na anamnese dos consulentes-indice envolve necessàriamente importante causa de êrro. Éste se verifica, porém, no sentido da omissão, pois, por um lado, se trata de características fàcilmente acessiveis à observação do leigo e, por outra parte, só consideramos presente a condição respectiva quando o informante não hesita em mencioná-la, em geral espontâneamente, e quando a ocorrência era assaz acentuada para não padecer dúvida.

Alguns dos traços acima referidos se limitam forçosamente a um grupo particular de consulentes e por isso só figuram englobados na tabela 1 devido ao fato de incidirem também na família dos examinandos. Aludimos aos que entendem com as mães, ou as gestantes que transpuseram a primeira gravidez - no total de 115 entre as 300 matrículas aqui consideradas. Neste conjunto peculiar de consulentes arrolamos dados que ultrapassam de muito, ao que parece, a incidência média: respectivamente, abôrto espontâneo em $27,8 \%$, parto de natimorto em $13 \%$, parto operatório em $3,5 \%$ e eclâmpsia igualmente em $3,5 \%$. Apenas esta última condição se filia atualmente sem dificuldade ao ciclo heredobiológico da epilepsia. Mas, o fato de que, entre as consulentes aí consideradas, predominam elementos a nosso ver epileptóides, nos leva a supor que também aquelas três primeiras ocorrências possam entrar para o mesmo ciclo. Cumpre ainda salientar duas anotações relativamente muito freqüentes nessa série de 115 matriculadas: parto de prematuro e parto de gêmeos, cada qual com a incidência de $9,6 \%$. Nāo dispomos ainda de cifra de referência para com a primeira ocorrència, mas podemos afirmar que o nascimento de gêmeos é muito mais comum nesse grupo do que na população média.

Assim é que encontramos, nas estatísticas correspondentes que fazem fé, a proporção de $1,2 \%$ de gêmeos sôbre o total de partos: a de Hellin, em 1895, 
estabelece - segundo refere Mayer " - a freqüência de 1:80 e a de Stock 16 a de 1:83. O fato de ser esta última computada sôbre quase 29 milhōes de partos registrados em países diversos - Inglaterra e Gales, Canadá, Estados Unidos da América do Norte - e entre 1931 e 1948, e o de concordar com o postulado de Hellin, mostram que êste assinala fenômeno biológico não sujeito a variaçōes regionais. Comparado a esta proporção de $1,2 \%$ o índice de geminação que anotamos entre as 115 matriculadas da tabela 1 aparece muito elevado. Efetivamente, revendo as fichas anamnésticas sob êsse aspecto particular, apuramos até agora 11 partos de gêmeos no total de 325 *, o que perfaz a proporção de aproximadamente $3,4 \%$. Embora o material clínico aqui considerado seja muito pequeno e ainda careçamos de análise estatística, supomos que o desvio não deva ser atribuído a fatôres meramente ocasionais.

Igualmente digno de nota parece-nos o indice de natimortos em relação a essas 115 consulentes: a revisão, ainda não ultimada, revela 28 ocorrências dessa ordem sôbre o total de 325 partos, donde a incidência de $8,6 \%$. Devemos lembrar que tal fenômeno pode estar ligado a causas eventuais, como a nosso ver o indica o recente trabalho de Stock, acima citado ${ }^{16}$ : para o total de partos revisados ali no periodo de 5 anos, ocorriam 2,6\% de natimortos em Inglaterra e Gales e $2,0 \%$ no Canadá. Portanto, para avaliarmos o significado do número de natimortos mencionados naquelas nossas matrículas dependemos ainda de estatísticas locais.

Essa incidência elevada de natimortos, de abortos, de distócia fetal, deve ser analisada detidamente em relação aos fatôres genéticos, principalmente devido à tendência médica ainda acentuada em nosso meio para interpretar as duas primeiras condições como devidas à sífilis - mesmo ante a negatividade de reações sorológicas - e a última como causa de dificiência mental ou de epilepsia. Não só, portanto, a assistência médica direta, mas principalmente a possibilidade de prevenção eugênica, tornam indispensável a correta apreciação heredobiológica de tais fenômenos patológicos. Por ora, e salvo correção dos achados mediante a indispensável análise estatística, a nós nos parece provável que tais tendências se prendam ao ciclo da epilepsia.

Outro grupo que podemos desmembrar do material clínico aqui considerado, é o dos menores. O estudo dos traços da personalidade e das várias ocorrências clínicas correspondentes é o que resumimos na tabela 2 :

- Ao enviarmos os originais para a presente publicação, tal revisão abrangia 2.018 gestações terminadas, das quais 57 gemelares: o indice respectivo caira, portanto, para $2,8 \%$, conservando-se, todavia, ainda elevado. Devemos mencionar que várias dentre os consulentes aí compreendidas - no total de 512 - já haviam completado nova gravidez por ocasiāo da revisāo (30-12-1955) e ainda não tinham comparecido para verificação. 


\begin{tabular}{|c|c|c|c|}
\hline & Incidêencia & $\begin{array}{c}\text { Em números } \\
\text { absolutos }\end{array}$ & $\begin{array}{c}\% \text { sôbre o } \\
\text { grupo }\end{array}$ \\
\hline 1 . & Terror noturno ..... & 28 & 33,3 \\
\hline 2. & "Ausência" psiquica ................ & 27 & 32,1 \\
\hline 3. & Convulsões sem desencadeante evidente $\ldots \ldots \ldots \ldots$ & 22 & 26,2 \\
\hline 4. & Hiperatividade $\quad \ldots \ldots \ldots \ldots \ldots \ldots \ldots \ldots \ldots \ldots$ & 21 & 25,0 \\
\hline 5. & Irritabilidade $\ldots \ldots \ldots \ldots \ldots \ldots \ldots \ldots \ldots \ldots$ & 20 & 23,8 \\
\hline 6. & 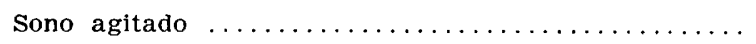 & 15 & 17,8 \\
\hline & Crises de "birra" $\ldots \ldots \ldots \ldots \ldots \ldots \ldots \ldots \ldots \ldots \ldots$ & 13 & 15,4 \\
\hline 8. & 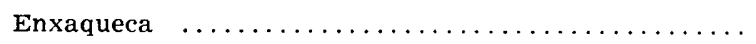 & 13 & 15,4 \\
\hline & Equivalentes comiciais atípicos $\ldots \ldots \ldots \ldots \ldots \ldots$ & 13 & 15,4 \\
\hline & Hiperemotividade $\ldots \ldots \ldots \ldots$ & 13 & 15,4 \\
\hline & Retardo escolar ............ & 11 & 13,0 \\
\hline & 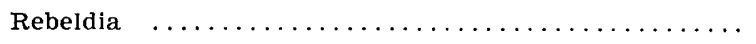 & 10 & 12,0 \\
\hline & 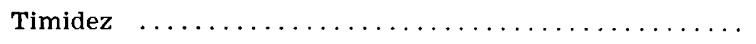 & 9 & 10,7 \\
\hline & Repentes de agressividade $\ldots \ldots \ldots \ldots \ldots \ldots \ldots$ & 8 & 9,5 \\
\hline & Sonambulismo $\ldots \ldots \ldots \ldots \ldots \ldots \ldots \ldots \ldots \ldots \ldots \ldots \ldots \ldots \ldots \ldots$ & 8 & 9,5 \\
\hline & Déficit de desenvolvimento intelectual $\ldots \ldots \ldots \ldots$ & 7 & 8,3 \\
\hline & Convulsões esporádicas $\ldots \ldots \ldots \ldots \ldots \ldots \ldots \ldots$ & 6 & 7,1 \\
\hline & Imaturidade afetiva $\ldots \ldots \ldots \ldots \ldots \ldots \ldots \ldots \ldots \ldots \ldots$ & 6 & 7,1 \\
\hline & Perda de fôlego $\ldots \ldots \ldots \ldots \ldots \ldots \ldots \ldots \ldots \ldots \ldots$ & 6 & 7,1 \\
\hline & Reação de pânico $\ldots \ldots \ldots \ldots \ldots \ldots \ldots \ldots \ldots \ldots \ldots \ldots \ldots \ldots \ldots$ & 6 & 7,1 \\
\hline & Desordens neurológicas discretas $\ldots \ldots \ldots \ldots \ldots \ldots$ & 5 & 6,0 \\
\hline & Terror noturno pregresso à primeira consulta $\ldots \ldots \ldots$ & 4 & 5,0 \\
\hline & Desordens metabólicas $\ldots \ldots \ldots \ldots \ldots \ldots \ldots \ldots \ldots$ & 3 & 3,5 \\
\hline 24. & Disgenesia do sistema nervoso $\ldots \ldots \ldots \ldots \ldots \ldots \ldots$ & 3 & 3,5 \\
\hline & 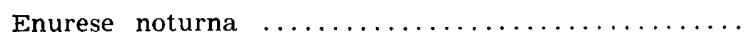 & 2 & 2,4 \\
\hline & Existência de gêmeos na familia $\ldots \ldots \ldots \ldots \ldots \ldots$ & 26 & 30,9 \\
\hline & Probandos gêmeos $\ldots \ldots \ldots \ldots \ldots \ldots \ldots \ldots$ & 3 & 3,5 \\
\hline
\end{tabular}

Tabela 2 - Condições clínicas verificadas em 84 matriculas de menores.

Considerados êsses consulentes como grupo, arrolamos 25 itens clínicos diversos, dos quais 12 figuram na tabela 1 . Dentre as condições que se apresentam em mais de um décimo do grupo (em número de 13), figura em primeiro lugar o terror noturno, o qual ocorre em mais de um têrço dos matriculados; seguem-se-lhe em freqüência os lapsos de "ausência" psiquica, as crises convulsivas espontâneas, a hiperatividade, esta última comum à quarta parte dos menores. Irritabilidade acentuada e agitação durante o sono eram mencionadas em relação, respectivamente, a 21 e 20 dos examinandos, ao passo que crises de "birra", enxaqueca, equivalentes atípicos de natureza comicial, hiperemotividade, incidiam 13 vêzes cada qual; a seguir, como se vê na tabela 2, arrolam-se, respectivamente, em 11, 10 e 9 instâncias o retardo escolar, a rebeldia e a timidez. 


\begin{tabular}{|c|c|c|c|c|c|c|}
\hline \multirow{2}{*}{\multicolumn{2}{|c|}{ Grupo cronológico }} & \multicolumn{2}{|l|}{ Meninos } & \multicolumn{2}{|c|}{ Meninas } & \multirow{3}{*}{$\begin{array}{r}\text { Tota } \\
\\
\quad= \\
4\end{array}$} \\
\hline & & Matrícula & Ne & Matricula & No & \\
\hline \multirow{4}{*}{\begin{tabular}{l}
$\Xi$ \\
$\Xi$ \\
$\Xi$ \\
$\Xi$ \\
\multirow{H}{*}{} \\
$\Xi$ \\
$H$
\end{tabular}} & De 1 a 2 anos & $\begin{array}{rr}56 & 80 \\
218 & \end{array}$ & 3 & 280 & 1 & \\
\hline & $\begin{array}{l}\text { De } 2 a-1 m \\
\text { a } 2 a-6 m\end{array}$ & $\begin{array}{r}31 \\
257\end{array}$ & 2 & $\begin{array}{l}175 \\
224\end{array}$ & 2 & 4 \\
\hline & $\begin{array}{c}\text { De } 2 \mathrm{a}-7 \mathrm{~m} \\
\text { a } 3 \text { anos }\end{array}$ & $\mid \begin{array}{cccc}52 & & & \\
241 & 245 & 288 & 292\end{array}$ & 5 & $\begin{array}{rrr}64 & & \\
137 & 185 & 198 \\
293 & & \end{array}$ & 5 & 10 \\
\hline & $\begin{array}{c}\text { De } 3 a-1 m \\
\text { a } 3 a-6 m\end{array}$ & 246 & $\begin{array}{lllllllll} & & & l & \end{array}$ & $\begin{array}{c}39 \\
271282\end{array}$ & 3 & 4 \\
\hline \multicolumn{2}{|r|}{ Total do grupo } & $\ldots$ & 11 & & 11 & 22 \\
\hline \multirow{4}{*}{$\begin{array}{l}0 \\
0 \\
0 \\
0 \\
0 \\
0 \\
0 \\
1 \\
0 \\
1 \\
0\end{array}$} & $\begin{array}{c}\text { De } 3 a-7 m \\
\text { a } 4 \text { anos }\end{array}$ & $\begin{array}{l}127 \\
260\end{array}$ & 2 & $\begin{array}{ll}153 & \\
258 & 285\end{array}$ & 3 & 5 \\
\hline & $\begin{array}{c}\text { De } 4 \mathrm{a}-1 \mathrm{~m} \\
\text { a } 5 \text { anos }\end{array}$ & $\begin{array}{l}21 \\
140 \\
259300\end{array}$ & 4 & 279291 & 2 & 6 \\
\hline & $\begin{array}{l}\text { De } 5 \mathrm{a}-1 \mathrm{~m} \\
\text { a } 6 \text { anos }\end{array}$ & \begin{tabular}{|ccccc}
34 & & & & \\
201 & 210 & 268 & 269 & 275
\end{tabular} & 6 & $\begin{array}{l}164 \\
254\end{array}$ & 2 & 8 \\
\hline & $\begin{array}{c}\text { De } 6 \mathrm{a}-1 \mathrm{~m} \\
\text { a } 7 \text { anos }\end{array}$ & $\begin{array}{ll}125 & \\
242 & 299\end{array}$ & 3 & 278 & 1 & 4 \\
\hline & Total do grupo & $\ldots \ldots \ldots \ldots \ldots$ & 15 & & 8 & 23 \\
\hline \multirow{4}{*}{ 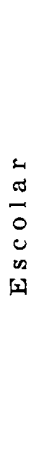 } & $\begin{array}{c}\text { De } 7 \mathrm{a}-1 \mathrm{~m} \\
\text { a } 8 \text { anos }\end{array}$ & 208227 & 2 & $\mid \begin{array}{rrrr}60 & 81 & & \\
142 & 159 & 165 & 186 \\
239 & & & \end{array}$ & 7 & 9 \\
\hline & $\begin{array}{c}\text { De } 8 \mathrm{a}-1 \mathrm{~m} \\
\text { a } 10 \text { anos }\end{array}$ & $\begin{array}{rccc}15 & 55 & 98 & \\
170 & & & \\
221 & 230 & 247 & \\
284 & 286 & 294 & 297\end{array}$ & 11 & $\begin{array}{rrrr}9 & 67 & & \\
124 & 154 & 183 & 191\end{array}$ & 6 & 17 \\
\hline & $\begin{array}{l}\text { De } 10 \mathrm{a}-1 \mathrm{~m} \\
\text { a } 12 \text { anos }\end{array}$ & 27 & 1 & $\begin{array}{rlll}90 & & & \\
176 & 188 & & \\
232 & 261 & 265 & 277\end{array}$ & 7 & 8 \\
\hline & $\begin{array}{l}\text { De } 12 \mathrm{a}-1 \mathrm{~m} \\
\text { a } 14 \text { anos }\end{array}$ & $\begin{array}{r}41 \\
225\end{array}$ & 2 & $\begin{array}{c}46 \\
235\end{array}$ & 3 & 5 \\
\hline \multicolumn{2}{|r|}{ Total do grupo } & $\ldots \ldots \ldots \ldots \ldots$ & 16 & & 23 & 39 \\
\hline \multicolumn{2}{|r|}{ Total geral } & 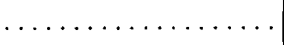 & 42 & & 42 & 84 \\
\hline
\end{tabular}

Tabela 3 - Distribuição cronológica das matrículas de menores. 
Condições clínicas

\begin{tabular}{|c|c|c|c|c|c|}
\hline \multicolumn{2}{|c|}{ Até $3 a-6 m$} & \multicolumn{2}{|c|}{$\begin{array}{c}\text { De } 3 a-7 m \text { a } \\
7 a\end{array}$} & \multicolumn{2}{|c|}{$\begin{array}{c}\text { De } 7 a-1 m \text { a } \\
14 a\end{array}$} \\
\hline Total & $\because i$ & Total & ro & Total & $\%$ \\
\hline
\end{tabular}

1. Terror noturno

2. "Ausência" psíquica ............

3. Convulsões sem desencadeante evidente

4. Hiperatividade

5. Irritabilidade

6. Sono agitado

7. Crises de "birra"

8. Enxaqueca

9. Equivalentes comiciais atipicos ..

10. Hiperemotividade $\ldots \ldots \ldots \ldots \ldots$

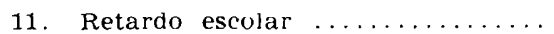

12. Rebeldia..$\ldots \ldots \ldots \ldots \ldots \ldots$

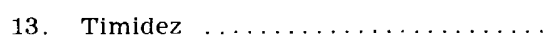

14. Repentes de agressividade ......

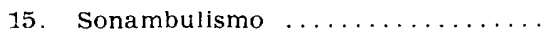

16. Déficit de desenvolvimento intelectual .............................

17. Convulsões esporádicas ........

18. Imaturidade afetiva $\ldots \ldots \ldots \ldots$

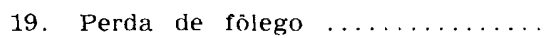

20. Reação de pânico

21. Desordens neurológicas discretas .

22. Terror noturno pregresso à prímeira consulta ................

23. Desordens metabólicas

24. Diagenesia do sistema nervoso ...

25. Enurese noturna Existência de gēmeos na família . Probandos gêmeos

\begin{tabular}{|c|c|c|c|c|c|}
\hline 14 & 77,3 & 9 & 39,1 & 2 & 5,1 \\
\hline 4 & 18,1 & 6 & 26,0 & 17 & 43,5 \\
\hline 8 & 35,3 & 8 & 35,0 & 6 & 15,4 \\
\hline 12 & 54,5 & 5 & 21,7 & 4 & 10,2 \\
\hline 2 & 9,0 & 5 & 21,7 & 13 & 33,3 \\
\hline 7 & 31,8 & 3 & 13,0 & 5 & 12,8 \\
\hline 12 & 54,5 & 1 & 4,2 & 一 & \\
\hline - & & 1 & 4,2 & 12 & 30,8 \\
\hline 4 & 18,1 & 1 & 4,2 & 8 & 20,4 \\
\hline 一 & & 1 & 4,2 & 12 & 30,8 \\
\hline - & & 一 & & 11 & 28,2 \\
\hline 1 & 4,5 & 1 & 4,2 & 8 & 20,4 \\
\hline- & & 2 & 8,6 & 7 & 17,9 \\
\hline$\ldots$ & & 一 & & 8 & 20,4 \\
\hline 一 & & 1 & 4,2 & 7 & 17,9 \\
\hline 2 & 9,0 & 一 & & 5 & 12,8 \\
\hline 4 & 18,1 & 2 & 8,6 & - & \\
\hline- & & $\longrightarrow$ & & 6 & 15,4 \\
\hline 6 & 27,3 & 一 & & 一 & \\
\hline 3 & 13,6 & 2 & 8,6 & 1 & 2,5 \\
\hline 3 & 13,6 & 1 & 4,2 & 1 & 2,5 \\
\hline - & & - & & 4 & 10,2 \\
\hline - & & 一 & & 3 & 7,7 \\
\hline 2 & 9,0 & - & & 1 & 2,5 \\
\hline- & & 1 & 4,2 & 1 & 2,5 \\
\hline 5 & 22,7 & 4 & 17,4 & 17 & 43,5 \\
\hline 一 & & 2 & 8,6 & 1 & 2,5 \\
\hline
\end{tabular}

Tabela 4 - Condições clínicas segundo os grupos de idade dos menores.

Diversas dessas manifestações clinicas estão plenamente reconhecidas como integrantes da constelação heredológica epiléptica: tais as "ausências" psíquicas, as convulsões, a irritabilidade fácil, a enxaqueca, os equivalentes comiciais, enumerados na tabela 2 sob números $2,3,5,8$ e 9 . Outras, dessa mesma faixa da tabela, coincidem na anamnese de nossos examinandos tanto em referência aos dados pessoais quanto à luz dos achados familiais com numerosos indícios de tendência epileptóide. Dai a impressão pessoal 
de que correspondem também a carga genética dessa modalidade. Referimonos aos itens 1, 4, 6, 7 e 10: terror noturno, hiperatividade, sono agitado, crises de "birra", hiperemotividade. 'Tal hipótese provisória nos guiou no manêjo dos casos clinicos em aprêço, conforme teremos ocasião de salientar adiante, e com resultados satisfatórios. Entretanto, repetimos, só nos será dado apreciar essas correlações adequadamente quando dispusermos de maior cabedal objetivo e o houvcrmos analisado estatisticamente. O mesmo raciocínio se aplica naturalmente a outras condições anotadas nessas fichas com menor freqüência - como registra a tabela 2 - e cuja significação heredológica poderá talvez afirmar-se mediante o ajuste estatístico: assim a imaturidade afetiva, as crises de perda de fôlego e as reaçōes de pânico. Tais condiçōes apareceram em menores em que outras séries de sintomas e traços de personalidade levavam a suspeitar de carga epileptóide: em vários dos consulentes em causa, que já retornaram para a revisão clínica, a medicação orientada nesse sentido produziu efeitos benéficos. Dessa forma, a escassa incidência de tais condições no grupo a que se refere a tabela 2 pode depender de fator meramente acidental e sobretudo do reduzido número de examinandos considerados.

De fato, a distribuição das várias condições clínicas entre os menores matriculados em nosso Serviço, estudados englobadamente, não exprime de modo adequado o valor relativo de cada uma delas. Por êsse motivo dividimos os consulentes dêsse grupo em três categorias de idade, o que já nos permite - mesmo carecendo de apreciação estatística, segundo já acentuamos - avaliar melhor o significado clínico de cada uma daquelas ocorrências. $\dot{E}$ o que ressalta do confronto estabelecido na tabela 4, a qual se refere aos três subgrupos cuja distribuição por ordem de idade aparece na tabela 3 .

Dessa forma, podemos notar que, no subgrupo médio da tabela 4, só aparecem as manifestações clinicas arroladas também em uma das categorias cronológicas vizinhas; ao passo que os dois extremos compreendem itens que lhes são próprios. Ademais, consideradas as cinco incidências percentuais mais freqüentes em cada divisāo da tabela 4, evidencia-se maior concordância, grosso modo, entre as duas primeiras, enquanto a de 7 a 14 anos tende a aproximar-se, pela textura e pelo grau de incidência das rubricas, da disposição encontrada no grupo geral de 300 consulentes e resumida na tabela 1 . Até o $5^{\circ}$ lugar de ocorrência percentual contam-se, para cada subgrupo, 6 itens, devido à igualdade na freqüência de dois dêstes. A categoria de 3 anos e meio a 7 anos exibe apenas 2 itens em comum com a terceira: "ausência" psíquica e irritabilidade; e 4 que figuram no subgrupo de menor idade - terror noturno, convulsões, hiperatividade, sono agitado. Peculiares ao têrmo cronoiógico inicial aparecem ai as crises de "birra" e de perda de fôlego; e ao de 7 a 14 anos, enxaqueca, hiperemotividade, retardo escolar, rebeldia, repentes de agressividade.

Comparada a ocorrência proporcional dos vários itens da tabela 4, nota-se que ela assinala a diversidade de reação entre os três subgrupos a que nos referimos. No primeiro predominam os fatôres terror noturno $(77,3 \%)$, hiperatividade $(54,5 \%)$, crises de "birra" $(54,5 \%)$, convulsões espontâneas 
$(36,5 \%)$, sono agitado $(31,8 \%)$ e perda de fôlego $(27,3 \%)$; no segundo, terror noturno em $39,1 \%$, convulsões espontâneas em $35,0 \%$, "ausências" psíquicas em $26,0 \%$, hiperatividade e irritabilidade, cada qual em $21,7 \%$, sono agitado em $21,7 \%$. Finalmente, na categoria de 7 a 14 anos, deparamos a seguinte gradação dos dados principais: "ausência" psiquica em $43,5 \%$, irritabilidade em $33,3 \%$, enxaqueca em $30,8 \%$, hiperemotividade igualmente em $30,8 \%$, retardo escolar em $28,2 \%$ e, cada qual em $20,4 \%$, rebeldia e repentes de agressividade.

Também entre os menores aqui considerados se aprecia em percentagem elevada $(30,9 \%$ c $)$ a menção de gêmeos na família. Esta particularidade de nosso material clínico nos leva a estudar mais detidamente semelhante problema, o qual assume, aliás, importância fundamental nas pesquisas de genética humana. Desde os trabalhos iniciais relativos à heredobiologia e à heredopatologia, os quais dentro em pouco adquiriram tal predominância nos conhecimentos científicos que levaram von Verschuer a erigir a gemelologia em campo médico especial, até os mais recentes, pōem em evidência a fertilidade de semelhantes verificações. Elas ensejaram, por um lado, a distinção entre fatôres endógenos e causas ambienciais em medicina interna ${ }^{1 i a}$, a compressão de entidades clínicas como a epilepsia 9 e, por outro, demonstrar que fenômenos biológicos especiais como a própria geminação dependem de tendência genética 2, 3a, 1ib. Em nosso cabedal clínico aqui mencionado os dados gemelológicos estão ainda em início e, por isso, nos limitaremos a essas alusões incidentes acima.

Ainda é cedo para avaliarmos objetivamente, mediante as anotações clínicas sôbre os consulentes a que hoje aludimos, a eficácia dessa orientação heredobiológica no setor da higiene mental. Entretanto, os resultados até agora consignados nas fichas de revisão nos parecem sugestivos e de molde a justificar algumas consideraçōes a respeito. Restringiremos os comentários às matriculas dos menores porque os fatos aí aparecem com mais nitidez e se reportam a menor número de manifestaçōes clinicas.

Dentre os menores a que correspondem as tabelas 3 e 4, 64 puderam ser revistos satisfatório número de vêzes porque matriculados antes de julho: dêsses, figuram 16 no $1^{\circ}$ grupo da tabela 4,14 no $2^{\circ}$ e 34 no $3^{\circ}$. Cotejando as anotações de revisão com as da respectiva ficha clínica inicial obtivemos os dados que resumimos a seguir.

Ao primeiro exame apuráramos a incidência de terror noturno em 17, dos quais 12 no primeiro grupo cronológico, 3 no segundo e 2 no último; havia agitação durante o sono em 10 , dos quais, respectivamente, 5,2 e 3 naquelas categorias de idade; reaçōes de pânico em 6 (respectivamente 3,2 e 1 quanto à distribuição nos subgrupos); "ausências" psíquicas em 20 (2: $4: 14)$, convulsões espontâneas em $17(5: 6: 6)$ e equivalentes diversos, atípicos, em $9(3: 0: 6)$. Em tôdas essas ocorrências concluíramos que o essencial era a medicação tendente a diminuir a excitabilidade do sistema nervoso: empregamos não só os barbitúricos menos tóxicos, em doses pequenas e fracionadas, mas também os derivados hidantoínicos e a fenilpropana, bem como 
sedativos preparados com o grupo urêico (bromural e nevanida). Igualmente a medicação nos pareceu fundamental nos 6 consulentes do grupo de 1 ano a 3,5 sujeitos a crises de perda de fôlego, bem como para aquêles dos dois grupos seguintes - respectivamente 1 e 8 - em que diagnosticáramos enxaqueca: para êstes consulentes, da mesma forma que em referência aos adultos, o preparado tri-orto-toloxi-propanadiol (Tolserol) foi de notável eficiência. Em todos os menores incluídos neste parágrafo os exames subseqüentes registraram o desaparecimento da condição mórbiđa em causa.

Em quatro outras ocorrências clínicas foi necessária a atuação medicamentosa, porém, para completar a orientação psicológica ou, melhor dito, psicoagógica para com o ambiente familial. Foram elas a hiperatividade (em que aquelas subdivisões cronológicas estavam representadas, respectivamente, com 8, 4 e 3 menores na revisão), as reações de "birra" (10:1:0) e, apenas dentro da faixa de 7 a 14 anos, repentes de agressividade em 6 menores e tardo escolar em 9. Dentre os 9 matriculados aqui mencionados, 6 se haviam beneficiado com a ação terapêutica combinada, até a data da última revisão. Com referência a tôdas as restantes rubricas o resultado favorável se assinalou para com a totalidade dos consulentes. A medicação instituida foi, aqui também, dirigida principalmente aos componentes epileptóides, os quais estavam em causa em quase tôdas as instâncias.

Finalmente, consideramos o subgrupo de manifestações em que não havia indicação para prescrições medicamentosas e nas quais a reorientação do ambiente domiciliar e a psicoterapia superficial foram suficientes. Uma e outra, entretanto - convém frisar - se desenvolveram de modo assaz precário devido a vários fatôres: o escasso nivel cultural, o desconfôrto e o desamparo econômico do lar proletário em nosso meio - e é de onde provém a maioria dos consulentes - a inviabilidade de psicoterapia individual em ambulatório público do tipo do nosso. Na realidade, a atuação do Serviço em relação a êste grupo de consulentes consistiu antes em explicar aos pais o modo de tratá-los nas diferentes situaçōes de conflito. Por exemplo, entre os que revelavam hiperatividade, ao todo 15 (8 na $1^{*}$ categoria cronológica, 4 na $2^{n}, 3$ na $3^{a}$ ) conforme referimos há pouco, a repressão a todo instante e o excesso de proteção por parte dos pais constituiam o principal fator pelo aspecto ambiencial. Na presente rubrica mencionaremos a rebeldia, a timidez, o desajustamento que se traduzia em deficiente aprendizado escolar, a enurese noturna. Com exceção da primeira condição - que abrangia consulentes das três subdivisões de idade (respectivamente na proporção de $1: 1: 5$ ) e da última, em que havia 1 menor na faixa intermediária — tratava-se aqui de crianças maiores. Pudemos anotar melhora acentuada da timidez em 5 dos 6 consulentes revistos, do contacto com a família e o ambiente escolar em 3 dos 4 que se haviam mostrado desajustados - ao passo que o $4^{\prime}$ necessitava do Serviço de Higiene Mental Escolar, para onde o encaminháramos; desapareceu a enurese noturna em 1 dos dois consulentes reexaminados e a rebeldia, antes acentuada, desapareceu ou se atenuou marcadamente nos 7 que haviam figurado inicialmente no item respectivo. Seria prematuro, porém, julgar da estabilidade dos resultados. 
Desejamos assinalar, a propósito dessas manifestações clínicas, que não consideramos essencial aí o resultado direto acaso conseguido, mas a oportunidade que oferecem ao Serviço para contactuar com a família do consulente. Êsse contacto serve para pôr em evidência, muita vez, a necessidade de examinar, aconselhar pelo prisma eugênico e mesmo medicar a pessoas que nem de leve sentiam que precisassem de semelhante auxílio. E, em regra, uma vez que tomam consciência dêsses problemas heredológicos, tais pessoas procuram conselhos e orientação quanto ao modo pelo qual devem nortear as relações de família e as diferentes questōes relativas à natalidade. $\mathrm{E}-\mathrm{o}$ que julgamos de alcance muito maior -- não raro indicam o Serviço a parentes e conhecidos que necessitam de assistência e orientação eugênica prématrimoniais.

Esta última, a ministração de conselhos eugênicos pré-nupciais, deve limitar-se a esclarecer os aspectos heredobiológicos da união conjugal em perspectiva, sem se imiscuir em problemas de outra alçada. $\hat{E}$ necessário deixá-lo bem patente. E assim o fazem, em exposição recente, Gianferrari e Morganti ${ }^{4}$ : "Fôrça é, pois, repetir que aqui consideramos apenas a consulta eugênica pròpriamente dita, isto é, relativa à prognose da transmissão de doenças hereditárias em senso estrito e entendida como atuação especialística médica, excluida tôda outra atividade consultiva conjugal pré-matrimonial atinente a outras especialidades médicas ou de ordem moral ou jurídica".

Com êsse espírito procuramos assistir mediante a orientação eugênica os consulentes do Serviço de Higiene Mental nos quais a indagação heredológica evidencia ser ela oportuna. Na grande maioria das vêzes nossos esclarecimentos são mais no sentido de tranqüilizar o entrevistando, pois a apreensão - quase sempre baseada nos preconceitos leigos ou médicos sôbre transmissão hereditária - constitui o motivo principal para a consulta espontânea a nosso Serviço. Assim, a genética humana pode servir à higiene da mente em duplo sentido: mediante o afastamento direto das causas de apreensões e a orientação quanto aos conflitos que originam tensão emocional e insegurança, mas principalmente através da profilaxia eugênica.

Naturalmente, o que temos conseguido - escasso no tocante à qualidade e também quantitativamente - vale apenas como indício de quanto a genética médica poderá realizar quando aplicada ao exame pré-matrimonial. Por sua vez, êste deverá entender-se como medida sistemática - embora nunca coercitiva - e entrosada em atuaçāo preventiva mais ampla, a fim de se tornar eficiente. Assim procuramos ${ }^{14}$ caracterizá-lo em 1945: "O exame médico pré-matrimonial deve, pois, a nosso ver, enquadrar-se num tríplice plano de ação eugênica: $1^{\circ}$ ) educar o público, dando-lhe conhecimentos práticos e acessiveis sôbre a heredologia humana, esclarecendo-o sôbre a função da família como unidade biológica, econômica e pròpriamente social, guiando-o quanto aos meios eficientes para proteger a caudal biológica da nação; $2^{\circ}$ ) modificar, mediante a colaboraçāo de grupos médicos pròpriamente clínicos e higienistas, ou de estudiosos da economia social, o nível de vida material e social da população; $3^{\circ}$ ) agir permanentemente junto aos poderes públicos para que os postulados eugênicos possam entrar em ação mediante 
as organizações assistenciais -- especialmente em relação à familia do alienado - ou a instituição de leis não draconianas, mas, ao contrário, aceitáveis pelo ambiente como proteção real" (pág. 43).

Como é evidente, o referido programa eugênico não poderá ser executado desde já senão quanto à primeira modalidade. Torna-se mister que a opinião pública seja preparada para sentir a necessidade das realizações que dependem dos poderes governamentais. E essa fase preparatória, que envolve ao mesmo tempo assistência médica e esclarecimento, terá de se desenvolver em Serviços como o que temos a nosso cargo, enquanto não haja organizações especialmente dedicadas à pesquisa médica nesse domínio particular. Esperamos que os dados aqui apresentados possam atrair a atenção dos colegas para o setor genético da higiene mental e mostrar a oportunidade de semelhante método de estudo e de ação preventiva.

\section{RESUMO}

Nos últimos 25 anos a genética humana tem assumido importância crescente na medicina geral e particularmente em psiquiatria. E, a nosso ver, a higiene mental só se torna eficiente quando norteada por aquela disciplina. Por ela orientamos nosso Serviço de Higiene Mental no Centro de Saúde de Santana, cujos dados clinicos apresentamos em resumo. Correspondem êles às primeiras 300 matriculas no Serviço, dentre as 317 efetuadas de fevereiro a 15 de julho de $1952 \%$. Frisamos que, embora tais dados sejam coligidos com critério clínico rigoroso, não foram ainda avaliados estatìsticamente quanto ao aspecto heredobiológico; portanto, nossas conclusões devem ser encaradas com as devidas reservas.

Todavia, merecem menção algumas ocorrências clínicas aí anotadas. AnaIisamos hoje apenas o ciclo epileptóide, que se revelou como predominante na linhagem dos consulentes, quer adultos, quer menores. Para os demais ciclos heredológicos ainda não dispomos de dados suficientes. Como indica a tabela 1, as condições clínicas mais freqüentes foram "ausências" psíquicas $(32 \%)$, irritabilidade $(20,6 \%)$, enxaqueca $(20 \%)$, equivalentes comiciais diversos, atípicos $(12,6 \%)$, hiperemotividade $(11 \%)$; o diagnóstico de neurose ocorreu 15 vêzes, ou seja em 6,9\% dos adultos. Os índices relativos são, porém, mais expressivos: entre as 115 consulentes que ultrapassaram a primeira gravidez anotamos abôrto espontâneo em $27,8 \%$, parto de natimorto em $13 \%$, parto operatório e eclâmpsia, cada qual, em $3,5 \%$. Duas outras condições merecem relêvo neste grupo especial: parto de prematuro em $9,6 \%$ e parto de gêmeos também em $9,6 \%$. O total de 11 pares de gêmeos se reporta a uma série de 325 gestações terminadas $* *$, o que perfaz o índice de $3,4 \%$, quando na população média êste é de $1,2 \%$. A tabela 2 reune as

* O total de matriculas no Serviço era de 2.060 em 31 de dezembro de 1955.

* A proporção era de 57 partos gemelares — inclusive abortos - correspondentes a 2.018 gestaçōes terminadas, quando da revisão das 512 consulentes desta rubrica, realizada em 30-12-1955. Logo, indice de $2,8 \%$. 
manifestaçōes mais freqüentes nos 84 menores, 42 de cada sexo: terror noturno, "ausências" psiquicas, convulsões, hiperatividade, irritabilidade ai predominam. Mas as tabelas 3 e 4 mostram que, no grupo cronológico de 1 ano a 3,5 (22 menores), dominam o terror noturno $(71,3 \%)$, a hiperatividade $(54,5 \%)$, as crises de "birra" $(54,5 \%)$, as convulsões $(36,3 \%)$; ao passo que, no de 7 a 14 anos, com 39 consulentes, prevalecem as "ausências" psíquicas $(43,5 \%)$, a irritabilidade $(33,3 \%)$, a enxaqueca $(30,8 \%)$, a hiperemotividade $(30,8 \%)$.

A compreensão heredobiológica dêsses vários elementos clínicos nos tem permitido orientar melhor a psicoterapia e o reajustamento familial, bem como recorrer simultâneamente à medicação necessária. A revisão de 64 menores matriculados até fim de junho de 1952 revelou: 1) a psicoagogia foi eficiente quanto à rebeldia, à timidez, ao desajustamento, em parte à enurese noturna; 2) foi mister associar-lhe a medicação nas crises de "birra", no retardo escolar, na agressividade; 3) a simples medicação foi eficaz nas "ausências", no terror noturno, nas reações de pânico, nas convulsões, na perda de fôlego, nos distúrbios durante o sono.

\section{SUMMARY}

Human genetic approach to mental health. Data on 300 counselees at the Public Health Clinic of Santana, São Paulo City.

For the last 25 years human genetics has steadily enlarged its place in internal medicine and especially in psychiatry. Mental hygiene, we believe, may only be efficient when oriented by this discipline. That is the line we follow in our Mental Health Service at the Public Health Clinic of Santana district, São Paulo City. This paper summarizes some data concerning the 300 counselees among $317^{*}$ seen there from February through July 15, 1952. Even though such data were obtained under close clinical criterion, they have not been statistically evaluated as regards heredobiological aspects: therefore, our conclusions must be taken as provisional. However, some of the recorded findings seem to deserve discussion.

Table 1 shows that most frequent conditions met with were: petit mal attacks (32 per cent), irritability (20.6 per cent), headache (20 per cent), atypical epileptic equivalents (12.6 per cent), hyperemotivity (11 per cent); neurosis was diagnosed 15 instances, i.e., in 6.9 per cent of the adults. Relative frequency rates are, however, more illustrative: out of 115 women who had completed at least one pregnancy, 27.8 per cent had miscarried, 13 per cent produced stillbirths, 3.5 per cent suffered eclampsia, 3.5 per cent had surgical delivery. Twin maternities were 11 in number, representing 3.4 per cent of a series of 325 confinements**, as compared to 1.2 per cent in the

* Last total of counselees, by December 31, 1955, was 2,060 .

** The combined number of twin couples, alive or stillborn, raised to 57 over a total of 2,018 completed pregnancies, corresponding to the 512 mothers comprised in this rubric and reported for follow-up by 12-30, 1955. Hence, the rate of 2.8 per cent. 
average population. Table 2 lists clinical entries for the 84 children of this material, 42 of each sex: night terror, petit mal attacks, seizures, hyperactivity, irritability, were the leading ones. As shown in Tables 3 and 4, for the age range 1-3.5 years (with 22 children), we recorded night terror in 71.5 per cent, hyperactivity in 54.5 per cent, temper tantrums in 54.5 per cent, seizures in 36.3 per cent; and for that of 7-14 years, assembling 39 children, chief disturbances were petit mal (43.5 per cent), irritability (33.3 per cent), headache (30.8 per cent), hyperemotivity (30.8 per cent).

The heredological meaning of the above clinical data has helped us in the selection for psychoterapy and home adjustment, as well as to institute the proper medication when needed. A follow-up of 64 children enrolled up to June 1952 disclosed that (1) psychological reorientation was efficient for obstinacy, shyness, maladjustment, enuresis; (2) it was needed to supplement it with medication in temper tantrums, retardation in school, aggressivity; (3) medication alone was enough for petit mal, night terror, panicky reactions, seizures, breathholding spells, sleep disturbances.

\section{BIBLIOGRAFIA}

1. CAUllery, M. - Les Conceptions Modernes de l'Hérédité. Flammarion, Paris, 1947. 2. DAHLBERG, G. -- Die Tendenz zur Zwillingsgeburt. Acta Genet. Med. Gemellol., 1:80, 1952. 3. GEDDA, L. - a) Studio dei Gemelli. Orizonte Medico, Roma, 1951; b) Genetica, Medicina e Costituzione. Acta Genet. Med. Gemellol., 1:1, 1952. 4. GIANFERRARI, L.; MORGANTI, G. - Apunti per una organizazione eugenica in Italia. Acta Genet. Med. Gemellol., 1:212, 1952. 5. KALLMANN, F. J. a) Twin studies in relation to adjustive problems in man. $\mathrm{Tr}$. Nẹ York Acad. Sc., $13: 270,1951 ; b)$ The genetics of psychoses; an analysis of 1,232 index families. Congr. Internat. Psychiat. Edit. Hermann, Paris, 1951. 6. KALLMANN, F. J.; ANASTASIO, M. A. - Twin studies on the psychopathology of suicide. J. Heredity, 37: 171, 1946. 7. KEMP, T. - The frequency of diseases affected by heredity in Denmark. Cold Spring Harbor Symp. Biology, 15:129, 1950. 8. KLEIST, K. - Uber zykloide, paranoide und epileptoide Psychoses und über die Frage der Degenerationspsychoses. Schweiz. Arch. f. Neurol. u. Psychiat., 23:3, 1928. 9. LENNOX, W. G. The heredity of epilepsy as told by relatives and twins. J.A.M.A., 146:529, 1951.10. MAYER, C. F. - Sextuplets and higher multiparous births. Acta Genet. Med. Gemellol., 1:118, 1952 e 1:242, 1952. 11. MULLER, H. J. - Our load of mutations. Am. J. Human Genetics, 2:111, 1950. 12. OSBORN, F. - Preface to Eugenics. Harper \& Brothers, Nova York, 1951. 13. SCHULZ, B. - Methodik der medizinischen Erbforschung. G. Thieme, Leipzig, 1936. 14. SILVEIRA, A. - O exame médico prénupcial pelo prisma da eugenia. Rev. Bras. Med. Públ., 1:39, 1945. 15. SNYDER, L. H. - a) Medical Genetics Duke. Univ. Press, Durham, 1941; b) Old and new pathways in human genetics. Am. J. Human Genet., 3:1, 1951. 16. STOCK, P. Recent statistics of multiple births in England and Wales. Acta Genet. Med. Gemellol., 1:8, 1952. 17. VERSCHUER, O. von - a) Erbpathologie. Steinkopff, Dresden, 1934; b) Ein altes und ein neues Problem der Zwillinsforschung. Acta Genet. Med. Gemellol., 1:180, 1952 . 